\title{
DESCRIPTION OF A NEW CONSTRUCTION OF HIGH PRESSURE STEAM BOILER.
}

\author{
BY Mr. J. FREDERIC SPENCER, OF LONDON.
}

This paper is communicated by the writer with the view of contributing to the general experience in generating steam of high pressure, say of $200 \mathrm{lbs}$. per square inch, in the belief that whilst the economy of more extended expansion is fully admitted, a safe, durable, and economical generator for ligh pressures is still a great desideratum. The boiler to which this paper refers was in some of its features invented and worked in America in 1852, and applied to work the steam pump of a fire-engine, lightness and rapid generation of steam being the chief requirements; and in December, 1856, the principle of mechanical circulation, one of the chief features of the boiler, was conceived and introdnced by Mr. Benson of Cincinnati, United States, and others. There are now about 45 of these boilers working satisfactorily in America, 10 of them being attached to stationary engines and 35 to steam fire-engines. A boiler capable of safely generating steam of 200 to $300 \mathrm{lbs}$. per square inch, which has been so successfully and extensively in operation, it was thought would be considered not unworthy the notice of the members of this Institution.

Safety, durability, and economy are the great requirements in a steam boiler; and practical engineers know too well by experience that, whilst it is not difficult to accomplish either of these singly, the combination of the three is extremety so, and especially where the steam to be generated is of very high pressure. Among the various boilers that have been constructed for generating steam of very ligh pressure, the small tubular form has been chiefly adopted, as being the strongest with the least weight of metal, and as also possessing the additional advantages of affording the largest heating surface in a 
given space, and containing almost a minimum quantity of water. One of the most important functions of a steam boiler is regular, uniform, and constant circulation of the water; so that as soon as the steam is formed it shall pass without delay into the steam chamber and the space it occupied be immediately refilled, with water. If from any cause this natural action is impeded, two injurious consequences result : ramely reduced evaporation and premature destruction of the conducting metal. It has been found that in land and marine boilers, in which there is always such a large amount of water in the boiler compared with the quantity evaporated, there is generally a very defective circulation, as evidenced by slow evaporation and rapid destruction of the conducting metal. In generating steam within small tubes containing a small amount of water, any deficiency of the feed may leave the tubes without water, in contact with a high temperature, and stop entirely or partially the proper circulating action so necessary in generating steam. The uncertainty of what may be termed natural circulation led to the invention and introduction of that which forms the distinctive feature of the boiler now to be described-mechanical circulation: by which ten to twenty times the quantity of water required for steam may be passed through the boiler within a given time.

The new boiler is shown in Figs. 1 and 2, Plates 52 and 53; Fig. 1 is a vertical section through the furnace and steam receiver, and Fig. 2 is a back elevation with part of the tubes in section. Above the furnace $F$ is arranged a series of tubes $T$ of about 1 inch or $1 \frac{1}{2}$ inch diameter and of any convenient length; these tabes are enclosed within a brick casing, or if preferred a water space casing, square in plan; they are covered in at the top by the uptake and chimney. Alongside and secured to the casing is the cylindrical steam receiver $R$, connected direct to the upper portion of the tubes by the pipes $\mathrm{L}$, and to the lower portion of the tubes by the pipe $\mathbf{E}$, the circulating pump $P$, and the pipe $G$. The boiler is divided into six distinct vertical sections, as shown in Fig. 2, each of which is separately connected below to a common feed or circulating pipe $\mathbf{C}$ communicating direct by the valve box $V$ and pipe $G$ with the circulating pump $P$, and above to the receiver $\mathrm{R}$ by the pipes $\mathrm{L}$. $A$ pipe $H$ is also fixed 
between the receiver and the common feed or circulating pipe $\mathbb{C}$, to allow the water in the receiver to pass into the tubes when the pump is not working and in starting the boiler.

The tubes and receiver are in the first instance partially filled with water pumped in by hand, as in other boilers, the communication between the lower and upper portions of the tubes and the receiver being open : the fire is then lighted, and as rapidly as the steam is generated in the tubes it passes through them into the receiver, until the whole of the water is heated and sufficient steam is generated to work the circulating pump. This pump, worked by a steam cylinder, is double-acting and of simple construction, having instead of the ordinary self-acting valves a $D$ slide valve without lap and worked by an eccentric, so that its continuous action can be thoroughly relied on ; this arrangement has in practice given every satisfaction. It will be evident that a small amount of power is required to work the circulating pump, since the pressure is almost equal on each side of the piston; so that whether this pressure be 100 or $500 \mathrm{lbs}$. per square inch, only the friction of the water has to be overcome in effecting the circulation. A boiler of 100 nominal horse power would require a circulating pump of only 7 inches diameter and 12 inches stroke, making 50 revolutions per minute. In addition to the circulating pump there is the ordinary feed pump attached to it, to supply the deficiency caused by the evaporation; and the ordinary feed pipe may be connected either to the circulating pump, as at $\mathrm{I}$, Figs. 1 and 2, or to the pipe $\mathrm{C}$, or to the receiver $\mathrm{R}$. The water gange is fixed on the receiver, and indicates the amount of water therein for the regulation of the feed. As soon as sufficient steam is generated to work the circulating pump, which in ordinary cases occupies about 20 minutes from cold water, the full working action of the boiler commences; and supposing 10 cubic feet of water are evaporated per hour, about 100 eubic feet are passed through the circulating pipe $\mathrm{C}$ and the tubes by the circulating pump. This 100 cubic feet per hour is discharged from the upper portion of the tubes into the receiver as mixed water and steam, the water falling to the bottom of the receiver and the steam remaining in the npper portion or steam space. It might be supposed that the steam would not be 
separated from the water with sufficient rapidity, and that very wet steam would be supplied: but practice and experience have proved that this is not the case; the separation is both rapid and distinct, and even when the water in the receiver has been allowed to rise to within a few inches of the top, the steam obtained has been quite as free from water as that usually supplied by ordinary land boilers.

Each section of the boiler has its own separate connexion with the receiver, and also with the common circulating pipe $\mathrm{C}$; and the flow of water through the latter connexions is regulated to any extent either by simple contractions or by cocks or valves; the contractions however are preferred. There are also cocks or stop valves on each of the upper connexions to the receiver, so that any section of the boiler may be shut off in case of injury, without in any way affecting the efficient working of the remaining sections. This is a most important feature of safety, and provides for easy repair either at the time of injury or at any subsequent period when convenient.

Figs. 3 and 4, Plate 53, show the tubes to a larger scale; they are screwed with a right and left handed thread so as by one movement to draw the two end bends together, and by this plan the union of the tubes in each section is performed without difficulty. It will also be noticed that each section of tubes can expand to any extent, being suspended on the vertical plates $\mathbf{S}$ by a small lug on each bend rivetted to them. For sweeping, cleaning, or removing any one of the sections hinged doors $\mathrm{D}$ are placed in front of the boiler, thus giving easy access at any time to any portions of the tubes. These boilers have been made both with brick casings, and water space casings; but the former plan is preferred on account of economy of first cost, safety, and improved combustion: when the casing is a water space, it may form the receiver.

Figs. 5, 6, and 7, Plate 54, show the arrangement of the boiler for marine purposes, with a distinct set of tubes $A$ for superheating or drying the steam after it has left the receiver.

The general construction and working action of the boiler having been described, a few remarks may be added as to its safety, durability, and economy. 
Safety :- there can be no question of the great strength of small cylindrical tubes of 1 or $1 \frac{1}{2}$ inch diameter; and as the receiver is not acted on by any high temperature, it can be maintained in full strength for an almost unlimited period. In consequence of the small amount of water in the tubes but little injury could arise from their giving way; and the receiver being removed from any external source of heat could not in the event of its bursting produce the dangerous percussive action resulting from the sudden release of highly heated water in a heated flue. Another element of safety is the facility with which any injured section can be disconnected from the rest of the boiler.

Durability:- - the only part of the boiler subject to great heat is the lower portion of the tubes, and it will be readily seen that the strong current supplied by the circulating pump tends to prevent not only deposit, but also any injury arising from want of water in the tubes. The tubes in one of these boilers that had been in constant work for 18 months with water largely impregnated with lime and other impurities were found on examination of several of them to be perfectly free from scale, any solid matter passing into the receiver from which it was easily removed. In order to ascertain the effect of working the boiler with salt water, some experiments have been made with one constructed in Newcastle by Messrs. Hawthorn. This boiler was formed of wrought iron tubes, 1 inch inside diameter, and had about 340 square feet of heating surface and 9 square feet of grate surface : it was kept in constant operation for 14 days and nights under a pressure of $80 \mathrm{lbs}$. per square inch, with salt water having about 5-33rds or 15 per cent. of salt in it, a saltness greatly in excess of that considered safe in marine boilers. Upon examination the lower tubes were found with an internal scale of 1-16th inch, whilst in the upper tubes a scale was hardly perceptible. This experiment was made with the view of trying how much scale could be deposited under the most unfavourable circumstances; and the result clearly proved that with the ordinary saltness in marine boilers the system of mechanical circulation would enable these boilers to work safely for a lengthened period. Although it is not intended at present to recommend the boilers to be continuously worked with sea water, it is satisfactory to know that, when used in combination with surface condensation, any 
temporary cessation of the pure water supply cannot injuriously affect thena.

Economy of Fuel:-it is well known that efficient combustion, thin conducting metal, large heating surface, and regular circulation will give a large evaporative duty. The result of some experiments made in the United States in June last gave evaporative duty of $11 \mathrm{lbs}$. of water per $\mathrm{lb}$. of fuel : it is however but fair to state that these experiments were made under unfarourable circumstances as to the working of the boiler.

Economy of Weight:-it is in marine boilers especially that weight is objectionable; and an ordinary marine boiler with 2000 square feet of heating surface is here compared with one of the same beating surface constructed on this tubular and circulating plan :-

New boiler. Ordinary boiler.

Weight of boiler, including brickwork, without water 22 tons. 20 tons.

Weight of water in boiler - . . . - $\quad 2$ " 19 "

Total weight of boiler and water . . . . $\overrightarrow{24}, \overrightarrow{39}$,

It will thus be seen that 40 per cent. of weight is saved; and in this comparison the heavy brick casing of the new boiler has been included together with the receiver and connexions.

Economy of Space :-taking again the new boiler with 2000 square feet of heating surface and an ordinary marine boiler having the same heating surface, the spaces occupied are as follows :-

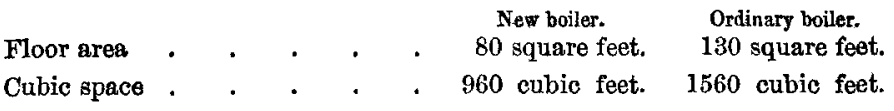

This comparison is greatly in favour of the new boiler, showing a saving of nearly 40 per cent. both in floor area and cubic space occupied.

Economy of Cost and Repair :-as to the cost of construction, experience has proved that in all cases the new boilers with circulating pump and receiver complete are made at a less cost that those of the ordinary tubular construction; and with reference to the cost of repair, it is almost entirely confined to the tubes and brick casing and therefore cannot be serious in amount.

One other advantage has to be referred to in these boilers in comparison with those in general use: namely rapidity in raising 
steam from cold water. In October 1858 some interesting experiments were made at St. Louis, United States, to test seven steam fire-engines, six of which had boilers on the circulating principle: in these six the steam was raised to $60 \mathrm{lbs}$. from cold water within 6 minutes. This is easily accounted for by the small quantity of water acted upon by the fire; but in general practice it is considered advisable to have a larger reserve of water, so that from 20 to 45 minutes may be necessary to raise steam. As the result of actual experience the following proportions have been arrived at for efficient generation of steam : for land boilers having 200 to 1000 square feet of heating surface there should be 1 cubic foot of steam and water space to every 22 square feet of heating surface; whilst in boilers having above 1000 square feet of heating surface the proportion should be 1 to 25 : for marine boilers the proportion of steam and water space to the heating surface should be 1 to 27 .

Mr. J. INshaw thought the tubular construction of boilers had several advantages, in compactness and lightness, and in increased extent of heating surface with diminished thickness of the conducting metal. He had made several tubular boilers many years ago, consisting of a series of concentric spiral coils of tubes placed upright in the furnace, each coil containing three spiral tubes of coarse pitch, and the coils being right and left handed alternately; there were 22 tubes in all, each about 27 feet long, of copper, $1 \frac{1}{4}$ inch diameter inside with $\frac{1}{16}$ inch thickness of metal. The spirals started at the bottom from a rertical water vessel placed at the back of the furnace, and returned at top into the top of the same vessel, which communicated by pipes with a receiver situated over the furnace and forming the steam chamber of the boiler, through which the uptake flue to the chimney passed for the purpose of superheating the steam; the water was kept 4 inches deep in the receiver, so as to ensure the tubes being always full of water. One of these boilers had been put up in Birmingham, supplying steam to a pair of 6 inch cylinders, working at about 6 horse power. 
The Chairman asked how long the boilers referred to had been at work, and how long the spiral tubes lasted.

Mr. J. Inshaw replied that the boiler erected in Birmingham had continued at work for two years without requiring any repairs to the tubes, but it was then heated red-hot and burnt down through wilful neglect on the part of the stoker. The firegate was hinged at the back and held up in front by a chain attached to a fusible plug in the receiver above, with the intention that the fire should be dropped in case of the water ever falling so low as to uncover the tops of the tubes; but the stoker having on one occasion purposely propped up the grate and neglected to fill up the supply of water, the whole of the tubes were burnt down. He had at first feared that the circulation of water through the tubes in regular work would not be sufficient to prevent their being burnt down, as there was only the natural circulation of the water to produce the necessary current through the tubes; but the tubes being each a continuous spiral, without any sudden turns, presented less obstruction to the passage of the water through them than would be the case in a boiler constructed like that described in the paper. One of the connecting pipes to the receiver had been replaced by a glass tube, that the circulation might be seen while at work; and a continued froth of mixed water and steam was seen to pass up into the receiver from the water vessel. The copper tubes in these boilers had proved durable, and did not become choked with deposit as he had feared would be the case ; for on cutting one of them in two after six months' work with fresh water there was found to be very little incrustation of deposit. The rapidity of raising steam in the boiler was remarkable as compared with boilers of the ordinary construction, steam being raised from cold water in 12 to 16 minutes easily; and the boilers had proved economical in fuel, on account of the superior conducting power of the thin copper tubes. In the boiler described in the paper he thought it would have been better to place the receiver higher up, above the level of the tubes, and expected that would give drier steam.

Mr. J. Manning thought there were a great number of joints in the boiler shown in the drawings, and feared the cast iron bends would suffer from expansion and contraction and be difficult to keep tight; 
it was a disadvantage in a boiler to have to depend upon a great number of joints all keeping sound and tight, and he enquired what was the amount of wear and tear in the boiler. He was much astonished at the extraordinary rapidity of raising steam that was stated in the paper, in so short a time as 6 minutes from cold water, and asked what fuel was used; in ordinary boilers the smoke from either wood or coal would hardly be got rid of in that time. The amount of incrustation in the tubes seemed remarkably small in the boiler described; for he had known of tubes of 1 inch inside diameter being made up to only $\frac{1}{8}$ inch diameter in two to six weeks' time.

Mr. SPENCER said the incrustation in the tubes would be materially prevented by the mechanical circulation of the water, which formed the main feature of the boiler now described; as long as the circulating pump continued at work the circulation of water was kept up and there was sufficient power in the current of water to sweep out any deposit from the tubes, so that little injury could result to them from that cause. With regard. to the expansion of the tubes, no difficulty was experienced with the joints or cast iron bends, and there was as much freedom for expansion as in a coiled spiral tube. The arrangement of spiral coils of tubing that had been mentioned might answer for a small boiler, where a small amount of heating surface was sufficient; but he thought it would not be practicable for a large boiler requiring from 3000 to 4000 square feet of heating surface. In the boiler described in the paper great facility for repairs was afforded by its division into a number of independent sections, each suspended by a centre attachment, so that any section could be detached and withdrawn without interfering with the rest of the boiler. As to the rapidity of raising steam, this depended mainly on the total quantity of water in the boiler, as the whole of it had to be heated to the boiling point before any steam was raised; and by diminishing this total quantity of water the time required for raising steam might be reduced to any extent desiręd. He remembered a locomotive for common roads being tried several years ago, in which steam was raised in 12 minutes from cold water, as there was but a very small quantity of water in the boiler. In the present boiler the quantity of water was very much less than in ordinary 
boilers; and the area of heating surface being at the same time increased by the tubular construction, the time necessary for raising steam was greatly reduced. In the case of the steam fire-engines to which this boiler was originally applied, a prize had been offered for the engine which should raise steam and throw a stream of water to a distance of 200 feet in the shortest time from the moment of lighting the fire with cold water in the boiler : in one instance this had been done with one of these boilers in less than 5 minutes, only 4 mins. 50 secs., the fire being made with the most rapidly burning materials, light pine wood and pitch.

Mr. E. A. CowPEn remarked that the tubular construction of boiler certainly afforded great facility for getting up steam in a short time, owing to the extent of heating surface; and by, reducing the quantity of water in the boiler the rapidity of raising steam might evidently be still further increased. He remembered an American fire-engine boiler that gained the prize for rapidity in raising steam, which was constructed mainly of pipes, one pipe forked into two and these again each into two more; but he did not think any such construction of boiler was practically useful for ordinary purposes, and it appeared applicable only for such cases as steam fire-engines, where the great points of importance were rapidity of raising steam and lightness of construction; in such instances durability was a minor consideration, and it did not matter so much if the boiler were burnt ont after a short time of work. For ordinary use however he thought it would not-be safe to have so small a quantity of water in the boiler; for to obtain regularity in the pressure of steam a considerable quantity of water was required as a reserve to fall back upon in case of deficient firing or over-firing. With respect to the principle of employing mechanical means to produce an artificial circulation of the water, he thought natural circulation was the safest to be depended upon ; for if the circulating parmp shovld get out of order or stop working from any cause, the whole of the tubes would be exposed to be burnt down, since the cireulation through them would cease.

Mr. SPENCER thought there was not any real ground for objection against the use of machinery for the purpose of generating steam, 
since experience proved that dependence was already placed with safety upon the constant action of simple machines under various circumstances. Where an efficient machine could be obtained he would prefer in some cases, and in the preserit instance, to rely upon it rather than upon an action produced by natural causes which might be liable to accidental interference: many good machines it was known would keep at work for 20 years without failing; and in the present instance he considered so simple a machine as the circulating pump might safely be relied upon for regular working. The principle of mechanical circulation carried out in this boiler appeared to him one of great importance, and worthy of special attention as a valuable improvement in steam boilers, since the circulation in ordinary boilers was so defective.

Mr. Benson said he had been practically acquainted with the working of tubular, boilers for many years; and all previous boilers having been dependent entirely upon natural circulation of the water, it had occurred to him that tubular boilers in particular could not prove successful in working unless a constant circulation were maintained through the tubes by mechanical means, so as to be unaffected by accidental ' circumstances; the uniform mechanical circulation would also enable steam to be raised more rapidly, and the rate of evaporation would be rendered more uniform. In a tubular boiler constructed with spiral tubes he should expect the tubes would last but a short time with natural circulation, if the evaporation were at all rapid, as the steam would be apt to keep back the water from the surface of the tubes; and such an arrangement could be made successful only by the adoption of a forced circulation of the water through the tubes, as he considered mechanical circulation was the essential feature of the tubular boiler. With the employment of mechanical circulation the tubes of the boiler described in the paper had been found to be remarkably free from incrustation ; on examining several of them after 18 months' work the interior surfaces presented the clear grey appearance of clean iron without any signs of dirt, showing plainly that any deposit contained in the water was effectually cleared out of the tubes by the mechanical circulation and carried over into the receiver. 
In the first attempts at designing the boiler a series of volute coils of tabes had been tried with about 20 coils, the lower tubes being inch diameter and increasing in diameter to 2 inches in the top coil: an arrangement of forked tubes such as had been referred to was also tried, but with these divided tubes it was found impossible to keep up a regular supply of water to all the tubes by the simple feed pump, and plain straight tubes were therefore substitated. There was still however too much hot water constantly in the receiver and too little water in the tubes, on account of the impossibility of keeping the tubes well filled with water by means of the natural circulation alone; and the idea of a forced circulation of the water through the tubes then occurred, and was carried out by the addition of a small circulating pump. Little power was required to work this pump, as it was only 3 inches diameter with a 10 inch stroke and there was the same pressure of steam on both sides of the pump, the only resistance to be overcome being the friction of the water in its passage through the tubes. The sharp bends at each end of the tubes increased the resistance, but had the advantage of impeding the motion of the water and thereby ensuring a thorough contact of the water with the entire extent of heating surface. The screwed ends of the tubes were made slightly conical, so as to jam tight into the cast iron bends, and at first a little linseed oil was applied to make the joint thoroughly steam-tight; but this was found not to be necessary, and it was only requisite to take care the screw threads were clean in screwing together, and then after a few days' working the joints were so tight that they frequently could not be unscrewed, but the ends of the tubes were twisted off before the screws would stir. In two boilers containing each 720 joints screwed in this manner, not one out of the whole 1440 joints leaked after first putting together. For replacing a defective tnbe in any section of the boiler, the union joints at top and bottom connecting it with the receiver were unscrewed, and the entire section taken out in about 5 minutes; the tube was then cut off at each end near the socket, and the two remaining end pieces were got out by cutting a longitudinal chase in them with a chisel and then collapsing them with strong tongs, without damaging the screw threads in the socket. The new tube to be put in was made 
in two lengths joined by a long screwed socket, to allow of getting it in without disturbing the other tubes. The whole operation was done in abont 20 minutes, as quickly as a tube could be replaced in ordinary tubular boilers. In the first boilers made the tubes had been placed rather too close together, with only $\frac{3}{4}$ inch spaces, which did not allow sufficient draught between them; they were now fixed with $1 \frac{1}{4}$ inch vertical spaces, but the horizontal spaces were left $\frac{3}{4}$ inch. Good combustion of the fuel with this construction of boiler was obtained by having the lowest row of tubes about 3 feet high above the grate.

The new boiler was specially designed at first for steam fire-engines, and was then made to contain only 3 cubic feet of water in the tubes and 6 cubic feet in the whole boiler. The boiler was kept standing ready for use, with no water in the tubes; and immediately that the fire-bell rang, a fire of very light pine wood was lighted under the boiler and half the water turned into the tubes; the engineman then worked the circulating pump by hand, and in 5 minutes the engine was ready for throwing water with $60 \mathrm{lbs}$. steam. In one of the trials made as to rapidity of raising steam from cold water, steam of $60 \mathrm{lbs}$. pressure was raised in as short a time as 4 mins. 35 secs. In all such cases the amount of water in the boiler was purposely very small; but boilers intended for stationary engines would have a larger quantity of water, and might be constructed to contain any quantity that was thought suitable: the time required for raising steam wonld then of course be increased, and for ordinary stationary engines 40 or 45 minutes might be required for getting up steam. A stationary boiler of this construction with 400 square feet of heating surface had been at work at Cincinnati for 16 months before he left America in June 1858, supplying steam to an engine driving a machine shop, and both engine and boiler were attended to by a boy 14 years old: for stopping during the dinner hour it was only necessary to stop the circulating pump, damp the fire, and shut the firedoor and ashpan, and the boiler then stood for an hour without any injury to the tubes.

With regard to the evaporative duty of the new boiler, an experiment had been made with one of the boilers in a steam fireengine in America, with 300 square feet of heating surface, and it evaporated $11 \mathrm{lbs}$. of water per lb. of coal; the pressure of steam was 
80 lbs. per square inch, and the fuel bituminous coal. In this case the draught through the furnace was weak, the chimney being only 6 or 7 feet high.

Mr. E. Jones asked whether any of the boilers were at work yet in this country, as he remembered haring seen one in process of manufacture at Wednesbury more than a year ago.

Mr. Spencer replied there were not any of the boilers working at present in this country, but two were being made, which would be got to work in London shortly. One of the boilers had been constructed at Newcastle, and had been tried there for 14 days continuously with salt water; and only $\frac{1}{16}$ inch thickness of deposit was found in the lower tubes at the end of that time, with scarcely any scale in the upper tubes, though the water used was much more salt than was allowed in marine boilers.

Mr. J. INsHAw observed that in reference to rapidity of raising steam he did not think this was a point of much advanlage for ordinary stationary boilers, because with so small a quantity of water the pressure would go down again as quickly as it was raised, and wonld be more affected by irregularity in the firing. He enquired how the proper proportion of water was ensured to each section of the new boiler without a separate circulating pump for each section.

Mr. Benson replied that the apertures of the branch pipes leading to each section of the boiler were regulated in area of passage to the required extent for ensuring an equal distribution of the water, the openings nearest the circulating pump being the smallest. Cocks had also been used for the purpose on each branch in some of the boilers, but he preferred to regulate the supply by the size of the aperture, by which the distribution of water was made permanently correct. The circulating pump worked with a simple slide valve with no lap, which kept up an uninterrupted current of water.

Mr. Spencer remarked that there had been a good practical trial of small tubes in the hot-water warming apparatus employed by $\mathbf{M r}$. Perkins of London, who had now had one set of the tubes in constant work for 12 years with only natural circulation of the water, without any injury to the tubes; it thus appeared that eren without the adoption of mechanical circulation tubes would last for a long time P 2 
without choking if taken care of, but with mechanical circulation any liability to incrustation was still further diminished.

Mr. Bessos observed that an essential point in this construction of tubular boiler was the use of a receiver from which the steam was drawn, for it would be impracticable to work such a boiler without the receiver, as the steam conld not be obtained dry if taken off direct from the tubes; and by increasing the size of the receiver the quantity of water contained in the boiler could be increased to any extent desired, while the area of heating surface remained unaltered.

The Chairman proposed a vote of thanks to Mr. Spencer for his paper, and also to Mr. Benson, which was passed.

The meeting then terminated. 


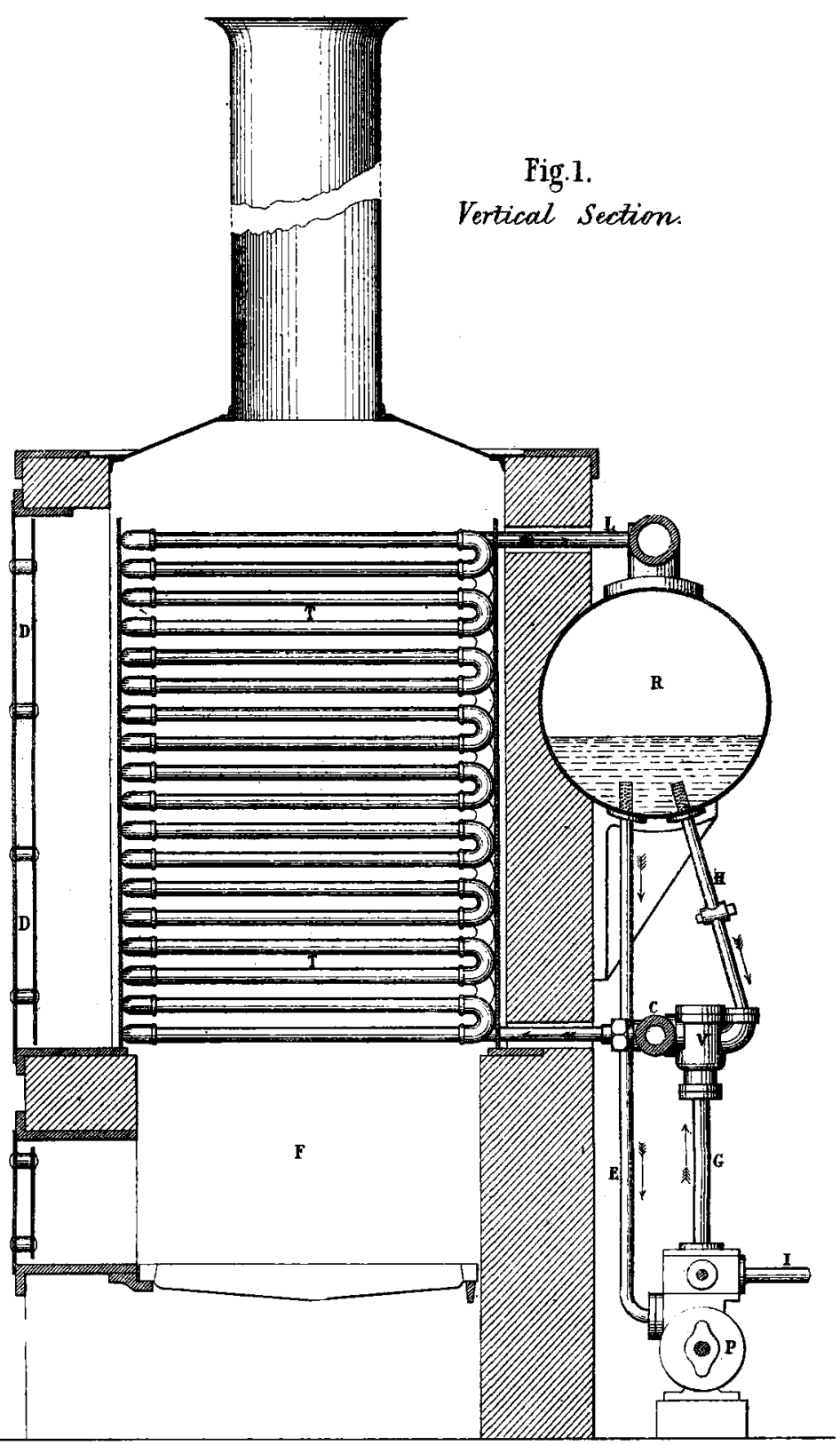

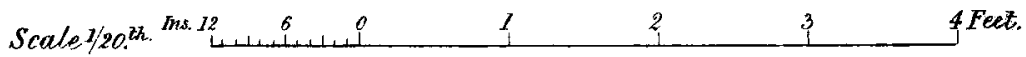


HICH PRESSURE' STEAM BOILER.

Plate 33.

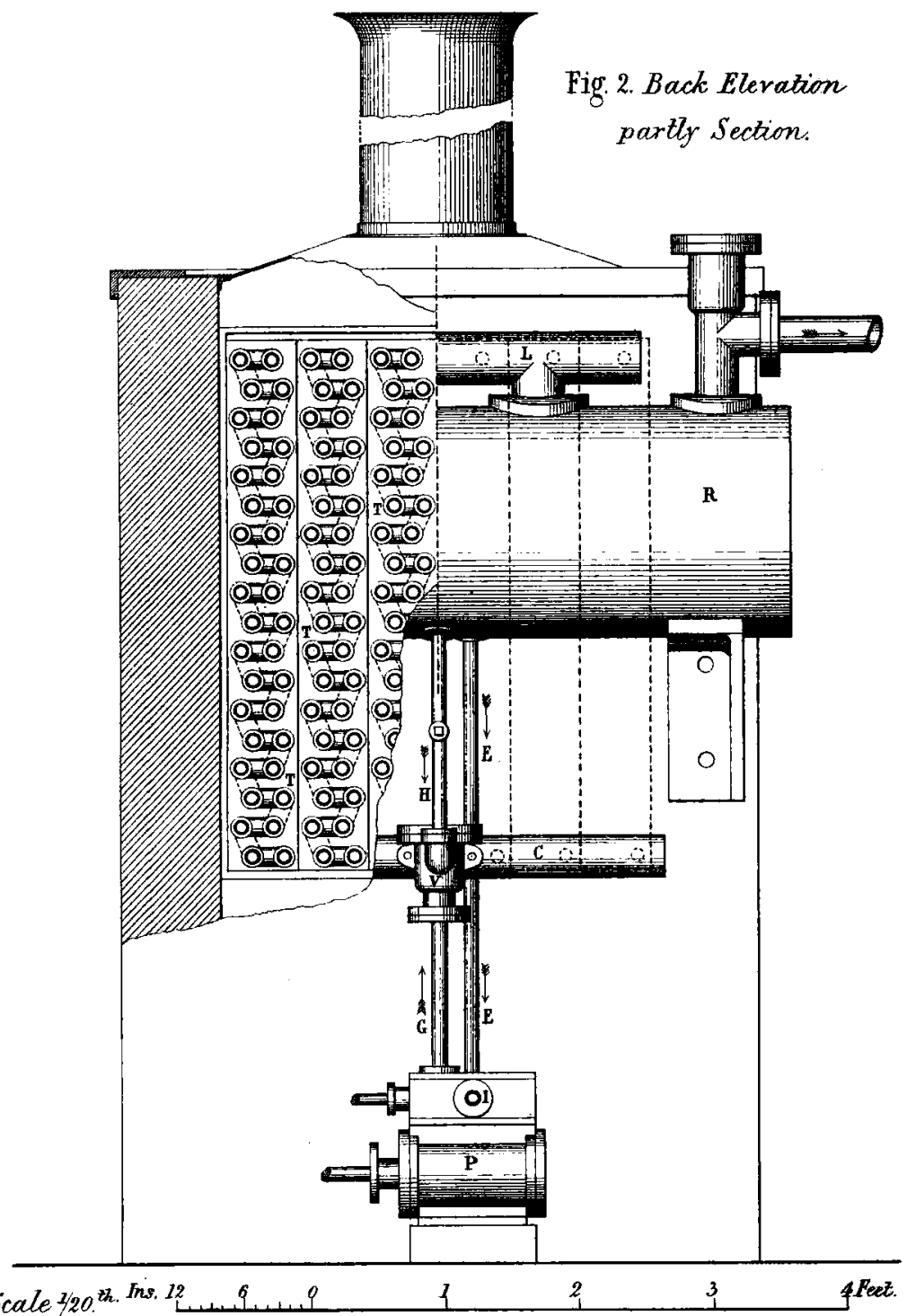

Scale 3/20 th. Ins.

Fig. 3.

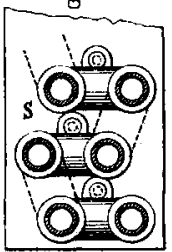

Fig. 4. Detail of Tubes, enlarged.

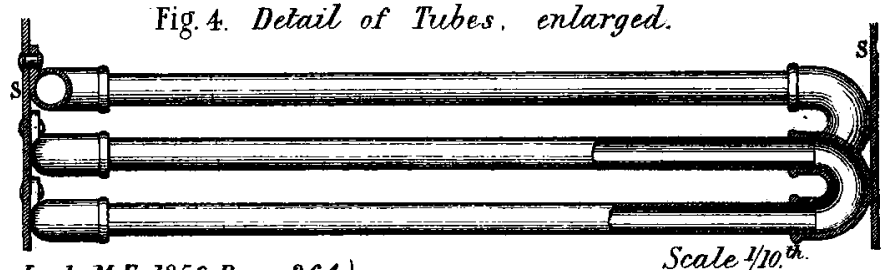

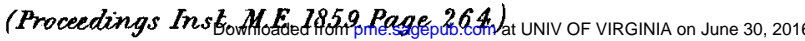




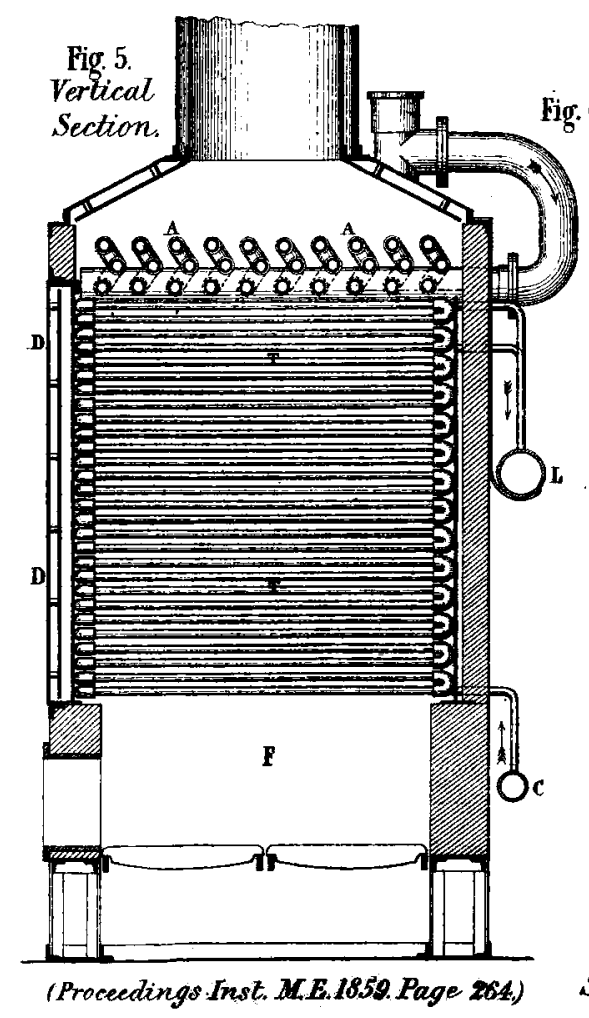

HICH PRESSURE STEAM BOILER.

Plabe 54.

Marine Doiler.

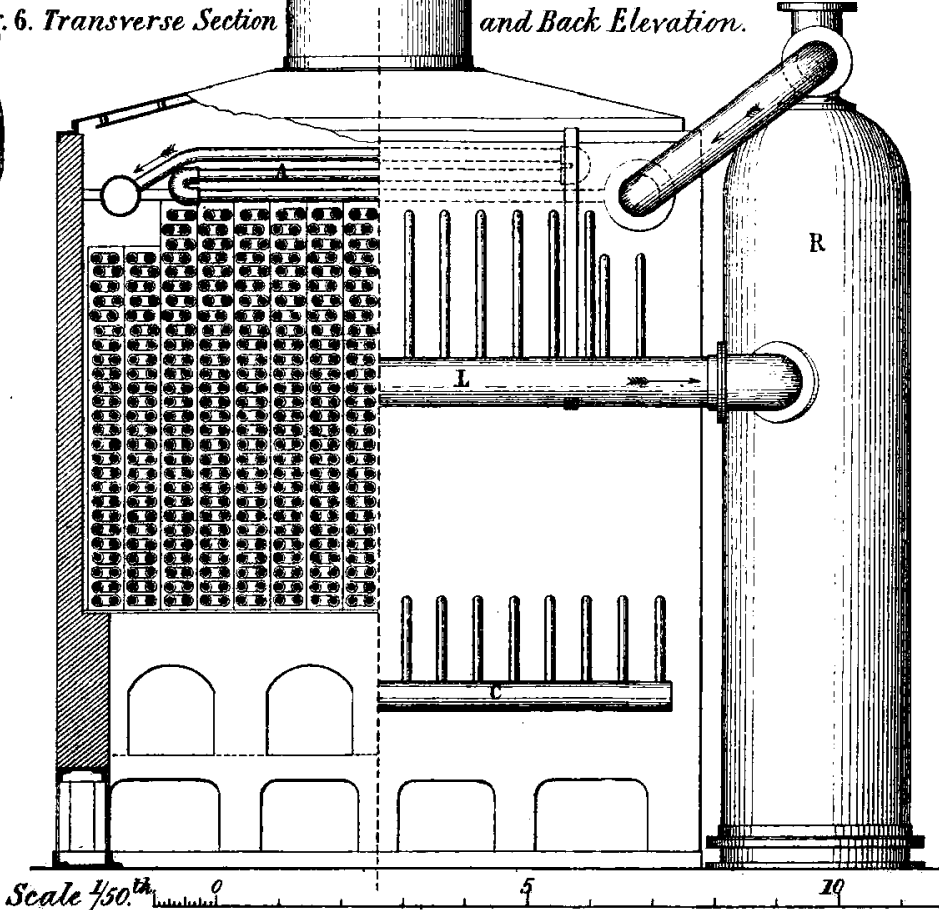

Fig. 7. Plan.

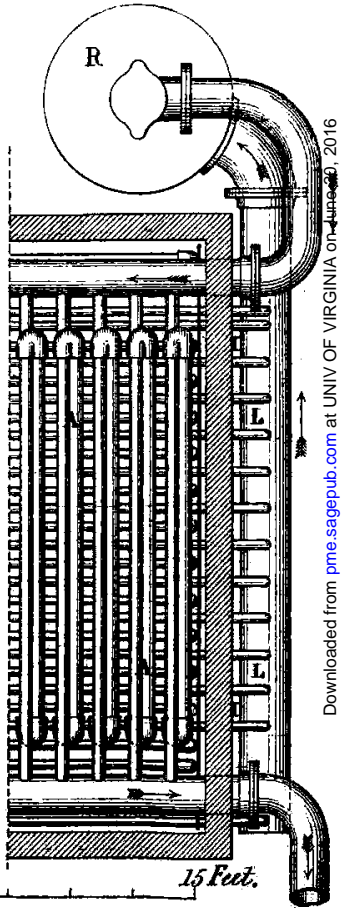

